\title{
Validation of Analytical Method for Quantification of Egg Cholesterol Using Reversed Phase-High Performance Liquid Chromatography-Multiwavelength Detector
}

\author{
Y. L. Maslukhah ${ }^{a}$, D. N. Faridah ${ }^{b, *}$, \& H. N. Lioe $^{b}$ \\ aGraduate Student of Department of Food Science and Technology, Faculty of Agricultural Technology, \\ IPB University (Bogor Agricultural University) \\ ${ }^{b}$ Department of Food Science and Technology, Faculty of Agricultural Technology, \\ IPB University (Bogor Agricultural University) \\ Kampus IPB Darmaga Bogor 16680, Indonesia \\ *Corresponding author: didah_nf@apps.ipb.ac.id \\ (Received 18-02-2019; Revised 13-06-2019; Accepted 18-06-2019)
}

\begin{abstract}
In this research, analytical method of cholesterol content in eggs by Reversed Phase-High Performance Liquid Chromatography-Multiwavelength Detector (RP-HPLC-MWD) was validated. Our experiment validated the modified method of AOAC 994.10:2012 to get a more simple and efficient analytical method of cholesterol content. The sample was saponified using $10 \% \mathrm{KOH}$ concentration for $15 \mathrm{~min}$ at $80{ }^{\circ} \mathrm{C}$, then this analytical method was validated. RP-HPLC-MWD condition was at $100 \% \mathrm{MeOH}$ as a mobile phase, flow rate of $1.0 \mathrm{~mL} / \mathrm{min}$, detection UV at 205 $\mathrm{nm}$, cholesterol was detected at $10.38 \pm 0.13 \mathrm{~min}$. As a result, the coefficients of determination for instrument and method linearities reached 0.9991 and 0.9912 , respectively. The limits of detection and quantification of RP-HPLC-MWD instrument were found at 5 and $10 \mu \mathrm{g} / \mathrm{mL}$, respectively, while the method-detection limit and quantification limit were 250 and $500 \mu \mathrm{g} / \mathrm{g}$ sample, respectively. Recovery values for the cholesterol analysis ranged from $98.62 \%$ to $112.26 \%$, with a precision of $1.05 \%-3.90 \%$. Additionally, intralab reproducibility was known to reach $3.27 \%$. This validated method can be applied for the analysis of cholesterol in various eggs available in the market.
\end{abstract}

Keywords: cholesterol; chromatography criteria; eggs; method development; reversed phase

\section{INTRODUCTION}

Eggs are one of the richest sources of cholesterol. Specifically, chicken eggs are highly favored in the diet (up to $99.51 \%$ ) compared to the other eggs, with a consumption rate of $0.122-2.119 \mathrm{~kg} /$ capita/week during 2007-2017 (Central Bureau of Statistics, 2017). Analysis of cholesterol in the food matrices in previous studies could use a spectrophotometer (Santi et al., 2015; Abdurrahman et al., 2016), but in general, the existing methods for assessing cholesterol content in food matrices are based on chromatographic technique. Gas chromatography (GC) was found to be more sensitive for determination of cholesterol in the food matrices (Ahn et al., 2012; Bavisetty \& Narayan, 2015; Lioe et al., 2013; Park et al., 2013; Souza et al., 2017; Stroher et al., 2012). Compared to HPLC, GC-based analysis for cholesterol may be hindered by limitations, i.e., time-consuming sample preparation and costly, since derivatization of cholesterol compounds and reliability test using internal standard must be first performed before being used. In addition, GC instrument is operated at a higher temperature than HPLC (Albuquerque et al., 2016; Chen et al., 2015), which possibly induces the formation of cholesterol oxides (Cais-Sokolinska \& Rudzińska, 2018;
Min et al., 2015). Hence, this present work was designed to evaluate the applicability of HPLC for quantifying cholesterol level in foodstuffs.

Diode array detector (DAD) or UV seemed to be the most desirable detector for cholesterol quantification (Ahn et al., 2012; Albuquerque et al., 2016; Bavisetty \& Narayan, 2015; Lioe et al., 2013; Stroher et al., 2012). MWD (Multi Wavelength Detector) constitutes one of the ultraviolet detectors capable of performing more sensitive and selective detection than fixed wavelength detector of UV-Vis and the other detectors such as ELSD and RI (Mariutti et al., 2008; Wolfender, 2009). Studies on the quantification of egg cholesterol using RP-HPLCMWD have not been reported. Mobile phase-acetonitrile and methanol-is often applied in RP-HPLC at UV detection of 195-210 $\mathrm{nm}$ and flow rate of 1-1.5 mL/min (Ahn et al., 2012; Albuquerque et al., 2016; Bavisetty \& Narayan, 2015; Stroher et al., 2012).

AOAC 994.10:2012 is a standard method for cholesterol analysis in foodstuffs by GC-FID instrument (AOAC, 2012a); however, the technique needs more samples, which in turn requires more chemicals and saponification time. A modified method for cholesterol analysis with less amount of sample can reduce saponification time and $\mathrm{KOH}$ concentration in the step of 
sample preparation. In addition, the use of an available standard method for the other purposes needs an additional step, i.e. validation. Therefore, this present work aimed to validate the simple modified analytical method of eggs cholesterol using RP-HPLC-MWD.

\section{MATERIALS AND METHODS}

\section{Chemicals and Reagents}

Cholesterol standard with $95 \%$ purity (Sigma Chemical Inc, USA). Methanol; $\mathrm{KOH}$; anhydrous $\mathrm{Na}_{2} \mathrm{SO}_{4}$; hexane and of pro-analytical grade from Merck (Darmstat, Germany) were used. Methanol of pro-analytical and liquid chromatography grade was obtained from Merck (Darmstat, Germany). Demineralized water, technical $\mathrm{N}_{2}$ gas, and PVDF filter membrane $0.45 \mu \mathrm{m}$.

\section{Preparation and Homogeneity Test of Sample}

The materials used in this study were broiler chicken eggs (Gallus sp.) as food matrices for analytical validation, and the other commercial eggs such as red local chicken eggs, duck eggs, quail eggs, and lowcholesterol chicken eggs were used to applicate the validated method. All of the egg samples were obtained from the local market, in Bogor, West Java, Indonesia.

The mixed whole eggs of broiler chicken then were put into a small plastic bag and sealed. All samples were stored in a freezer at minus $18^{\circ} \mathrm{C}$. Preparation of the other egg samples was carried out in the same way. Sample homogeneity was tested according to Sunanti et al. (2013). The tested parameter was moisture content, in duplicate. Moisture content analysis used the AOAC 925.30:2012 method (AOAC, 2012b).

\section{Instrumental Performance for Cholesterol Analysis by RP-HPLC-MWD}

Instrumental performance analysis used a serial cholesterol standard solution. The linearity of the instrument, the precision of peak area and retention time, peak symmetry of standard cholesterol and sample, the limit of detection and quantification of the instrument were evaluated. The linearity test of the instrument used a serial standard cholesterol solution at concentrations of $10,25,50,75,100,125,150,200 \mu \mathrm{g} / \mathrm{mL}$, in triplicate. This evaluation followed EURACHEM guidelines (2014).

\section{Instrumentation and Condition of RP-HPLC-MWD}

HPLC series Infinity Agilent Technologies 1200 (Agilent Technologies, Waldbronn, Germany), G1365D MWD (Multiwavelength Detector) series Agilent Technologies 1200 Infinity (Agilent Technologies, Waldbronn, Germany), reversed phase column ZORBAX Eclipse XDB-C ${ }_{18}(150 \mathrm{~mm} \times$ id $4.6 \mathrm{~mm}, 5 \mu \mathrm{m})$ (Agilent Technologies, USA), $50 \mu \mathrm{L}$ syringe (Agilent Technologies, Santa Clara, USA), $20 \mu \mathrm{L}$ sample loop Rheodyne (IDEX Health \& Science, Oak Harbor, USA). The mobile phase composition, flow rate, and wave- length were used according to the selected good chromatographic condition of RP-HPLC-MWD as a result of our experiment before (experiment data were not presented). Methanol (100\%) was used as mobile phase at a flow rate of $1.0 \mathrm{~mL} / \mathrm{min}$ in isocratic mode and total run time was $15 \mathrm{~min}$ at room temperature. Analytes were detected using multiwavelength detector (MWD) at a wavelength of $205 \mathrm{~nm}$.

\section{Preparation of Cholesterol Sample (Modification of AOAC 994.10, 2012a)}

The initial step of sample preparation was saponification. In a $50 \mathrm{~mL}$ tube, $\pm 1 \mathrm{~g}$ of whole chicken eggs were weighed. Ten milliliters of $10 \%(w / v)$ methanolic $\mathrm{KOH}$ solution were added and thoroughly mixed for $20 \mathrm{~s}$ in a vortex, then the samples were blown under nitrogen for $10 \mathrm{~s}$. The mixtures were heated in a water bath at $80^{\circ} \mathrm{C}$ for $15 \mathrm{~min}$. After heating, the samples were cooled at room temperature for $15 \mathrm{~min}$. Afterward, these mixtures were extracted three times with $10 \mathrm{~mL}$ of hexane, each addition of $10 \mathrm{~mL}$ hexane was mixed in a vortex thoroughly for $20 \mathrm{~s}$. The upper phases (hexane phase) were transferred to the $25 \mathrm{~mL}$ tube, then the lower phases (water phase) were extracted again with hexane in the same way. Around $25 \mathrm{~mL}$ of cholesterol extracts were transferred to a $100 \mathrm{~mL}$ separator flask and the tube was rinsed with $2 \times 1 \mathrm{~mL}$ hexane. Furthermore, the solution was rinsed using $3 \times 10 \mathrm{~mL}$ of demineralized water. The last of residual rinse water was dripped with phenolphtalein $1 \%$ until the $\mathrm{pH}$ was neutral. Then the rinsed hexane phases were filtered with filter paper which was added $5 \mathrm{~g}$ of anhydrous $\mathrm{Na}_{2} \mathrm{SO}_{4}$. The cholesterol extracts were dried under nitrogen. Afterward, the dried cholesterol was redissolved in $0.5 \mathrm{~mL}$ of hexane then added with methanol (mobile phase HPLC) until the total volume of the solution was $5 \mathrm{~mL}$. After that, this solution was filtered with a $0.45 \mu \mathrm{m}$ PVDF membrane, then diluted 5 times. Finally, the aliquot $(20 \mu \mathrm{L})$ was injected into HPLC-MWD.

\section{Method of Validation}

The linearity of the method, specificity, the precision of area and retention time to evaluate the behavior of chromatogram, accuracy and precision, method detection limit, and intralab reproducibility were evaluated according to EURACHEM (2014) and AOAC (2012c, 2016) guidelines. The linearity method was carried out by a serial spiked sample of chicken eggs at concentrations of 250, 500, 3011, 4014, and $5018 \mu \mathrm{g} / \mathrm{g}$ in triplicate. Method linearity was evaluated by linear regression analysis with plotting peak areas (mAU*s) versus spiked concentrations ( $\mu \mathrm{g} / \mathrm{g}$ sample), then the determination coefficient $\left(\mathrm{R}^{2}\right)$, slope, and intercept were evaluated. Specificity was conducted by comparing the chromatogram of pure standard cholesterol, unspiked egg samples, and spiked egg samples. Furthermore, the accuracy and precision of the method were determined after spiking eggs with cholesterol standard at concentrations of $500 \mu \mathrm{g} / \mathrm{g}$ and $5018 \mu \mathrm{g} / \mathrm{g}$, each was assessed in seven replications. Mean, standard deviation (SD), 
and relative standard deviation (RSD) for each spiked sample were calculated.

Furthermore, the method of detection limit (MDL) was determined from the method linearity curve of the relationship between the standard deviation values of three spiked samples at concentrations of 5018, 3011, and $500 \mu \mathrm{g} / \mathrm{g}$, in triplicate. MDL curve linearity was evaluated by linear regression analysis, plotting SD of read cholesterol standard from each concentration (y axis) versus cholesterol spiked concentrations ( $x$ axis). The $\mathrm{SD}_{0}$ value was intercepted, MDL value was calculated as $3 \times \mathrm{SD}_{0}$, then the values were verified. Intralab reproducibility of the method was determined by analyzing unspiked egg samples on three different weeks by preparing three samples each week. The intralab reproducibility of the method was good if RSD analysis (\%) less than RSD Hortwitz (\%).

\section{Statistical Analysis}

Cholesterol contents and descriptive statistics were calculated using the Microsoft Excel 2013 program. Statistical analysis was analyzed using IBM SPSS 22.0 (SPSS Inc, Chicago). Evaluation of cholesterol contents among weeks in intralab reproducibility test was analyzed by One way-ANOVA test, followed by Duncan test. $\mathrm{P}$ value $<0.05$ was statistically significant.

\section{RESULTS}

\section{Instrumental Performance of RP-HPLC-MWD for Cholesterol Analysis}

Serial cholesterol standards were used in the instrumental-performance analysis. The calibration curve was determined with concentrations of $10-200 \mu \mathrm{g} / \mathrm{mL}$, while the slope and intercept of linear regression obtained were $11.515 \pm 0.220$ and $1.518 \pm 9.643$, respectively. The relationship between standard concentrations and peak area displayed the desired linearity, with $\mathrm{R}^{2}(0.9991)$ of $>0.99$ (AOAC, 2012c). The LOD and LOQ instruments were 5 and $10 \mu \mathrm{g} / \mathrm{mL}$. The concentration of cholesterol standard at $5 \mu \mathrm{g} / \mathrm{mL}$ could be detected by the instrument but had poor precision (Table 1). However, at 10 $\mu \mathrm{g} / \mathrm{mL}$ standard cholesterol concentration, its precision and accuracy have fulfilled the acceptability range of AOAC 2016 (Table 1) and good behavior chromatographic, the precision of area and retention time < $2.00 \%$, that was recorded at $1.89 \%$ and $0.39 \%$, respectively $(n=6)$. In addition, the peak symmetry of standard cholesterol and sample were 0.99 and 0.75 , respectively.

\section{Sampling}

Based on the homogeneity test, resulting in F-test statistic (2.94) < F table (3.50). Therefore, it can be stated that broiler chicken eggs used in this study are considered as homogeneous.

\section{Validation of Cholesterol Analytical Method}

Method linearity. The method linearity was linear over the range of $250-5018 \mu \mathrm{g} / \mathrm{g}$ sample. The slope and intercept were obtained at $0.3734 \pm 0.0085$ and $81.01 \pm 19.38$, respectively. The linearity of the developed method seemed to be satisfied as was indicated by $\mathrm{R}^{2}(0.9918)>$ 0.990 (AOAC, 2012c), indicating that it gave a proportional response to the increase in the concentration of cholesterol analytes in the samples.

Specifity. Method specificity is observed by comparing the peaks from pure cholesterol standard, unspiked egg samples, and spiked egg samples. Retention time achieved at $125 \mu \mathrm{g} / \mathrm{mL}$ cholesterol standard, unspiked and spiked samples $(5018 \mu \mathrm{g} / \mathrm{g})$ were $10.38 \pm 0.13 \mathrm{~min}$, $9.49 \pm 0.01 \mathrm{~min}$ and $9.41 \pm 0.11 \mathrm{~min}$, respectively. In Figure 1a-c, spiked egg samples (5018 $\mathrm{\mu g} / \mathrm{g}$ sample) demonstrated higher peak and larger area than unspiked egg samples. In addition, the peak of pure cholesterol standard showed the lowest area and height. The higher concentration of cholesterol in sample accounted for higher and wider peaks as shown in the chromatogram output, but they were detected at the same time. This implies that our developed method demonstrates good specificity.

Method-detection limit (MDL) and method-quantification limit (MQL). The estimated method-detection limit was determined by using chicken egg samples spiked with standard cholesterol solutions at 500, 3011, and $5018 \mu \mathrm{g} / \mathrm{g}$, in triplicate. Linearity and determination coefficient were presented as follows: $y=0.0262 x$ +70.438 and $\mathrm{R}^{2}=0.8702$. Based on the results, $\mathrm{SD}$ and MDL reached 70.44 and $211.31 \mu \mathrm{g} / \mathrm{g}$, respectively. This value was determined as a theoretical MDL, because samples spiked with cholesterol standard at a concentration of $250 \mu \mathrm{g} / \mathrm{g}(\mathrm{n}=3)$ possessed an unacceptable accuracy, but it had an acceptable precision (RSD < RSD Horwitz, $4.52 \%$ ). The precision and accuracy of 250 $\mu \mathrm{g} / \mathrm{g}$ spiked sample reached $4.44 \%$ and $194.71 \%$, with the acceptable recovery of $85-110 \%$. Therefore, MDL in this research was $250 \mu \mathrm{g} / \mathrm{g}$. Then, the results showed that addition of cholesterol standard at the concentra-

Table 1. The limits of detection and quantification for instrument

\begin{tabular}{cccccc}
\hline $\begin{array}{c}\text { Chromatograpic } \\
\text { criteria }\end{array}$ & $\begin{array}{c}\text { Cholesterol content } \\
(\mu \mathrm{g} / \mathrm{mL})\end{array}$ & RSD $(\%)$ & $\begin{array}{c}2 / 3 \text { RSD Horwitz } \\
(\%)\end{array}$ & $\begin{array}{c}\text { Recovery }(\%) \\
\text { Acceptable recovery } \\
(\%)^{c}\end{array}$ & $\begin{array}{c}\text { A } \\
\text { LOD }^{\mathrm{a}}\end{array}$ \\
\hline LOQ $^{\mathrm{b}}$ & 10 & 22.57 & 8.26 & 113.44 & $75-120$ \\
\hline
\end{tabular}

Note: a LOD (Limit of Detection), bLOQ (Limit of Quantification), cAOAC (2016). 


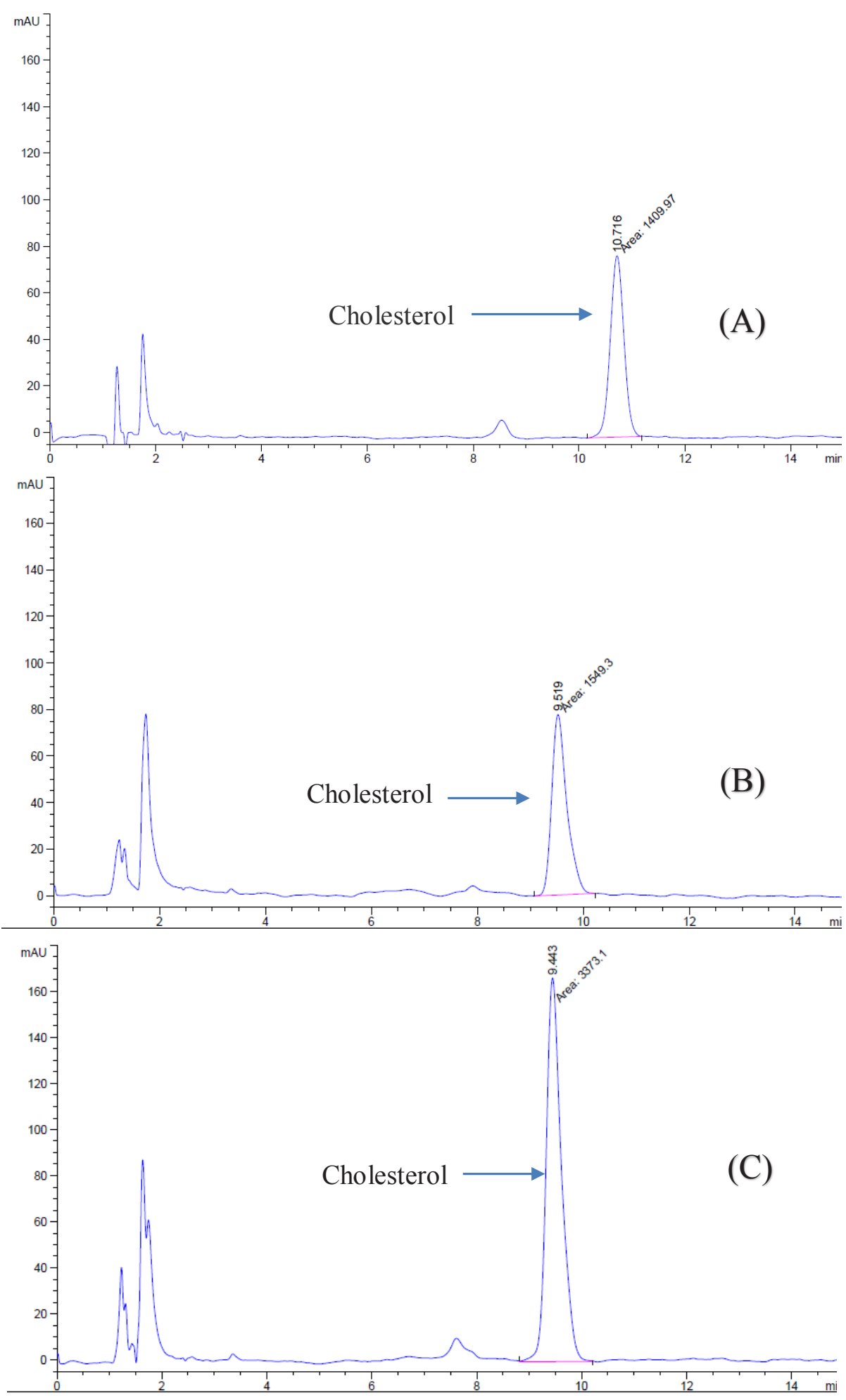

Figure 1. Chromatogram of cholesterol standard at $125 \mu \mathrm{g} / \mathrm{mL}$ (A), unspiked sample (B), spiked sample with $5018 \mu \mathrm{g} / \mathrm{g}$ sample (C)

tion of $500 \mu \mathrm{g} / \mathrm{g}(\mathrm{n}=7)$ could still be detectable with precision (1.04\%) less than 2/3 RSD Horwitz (3.00\%) and accuracy of $112.26 \%$. The concentration of spiked sample shows satisfied chromatographic behavior based on the precision of the area and retention time (RSD $\leq$ $2 \%$, with the precision up to $0.99 \%$ and $1.29 \%$, respectively. Furthermore, the average area and retention time reached $1760.20 \pm 17.58 \mathrm{mAU}^{*} \mathrm{~s}$ and $9.55 \pm 0.12 \mathrm{~min}(\mathrm{n}=7)$. RSD analysis $(<2 \%$ ) displayed a good suitability system of analysis method (JECFA, 2006). Therefore, the MQL was determined at $500 \mu \mathrm{g} / \mathrm{g}$ sample.

Accuracy. The accuracy of cholesterol analytical method was determined based on the recovery value of samples added with two levels of cholesterol standards at the initial step. The averages cholesterol found in 5018 $\mu \mathrm{g} / \mathrm{g}$ and $500 \mu \mathrm{g} / \mathrm{g}$ of spiked samples were 4948.70 and $561.30 \mu \mathrm{g} / \mathrm{g}$, respectively. The recovery values of two 
spiked concentrations were entirely presented in Table 2. Spiked sample with $5018 \mu \mathrm{g} / \mathrm{g}$ cholesterol fulfilled the acceptability range of AOAC (2016), i.e., 90\%-108\%. Conversely, the recovery at $500 \mu \mathrm{g} / \mathrm{g}$ spiked sample was found to be out of the acceptability range of AOAC (2016), i.e., $85 \%-110 \%$, even though the value was closed to the acceptability range.

Precision. This precision was evaluated by analyzing the spiked sample at 500 and $5018 \mu \mathrm{g} / \mathrm{g}$ sample. This procedure was repeated in a short period of time and injected on the one day for each group of concentration of spiked samples. Furthermore, RSD analysis and RSD Horwitz were compared, in which precision was expressed by RSD analysis. Table 2 shows that the precision values of both spiked samples are less than RSD Horwitz, which suggests that our cholesterol analytical method favorably affect precision.

Intralab reproducibility. In this study, the reproducibility tests used the same unspiked broiler chicken eggs as samples, instruments, operator at different times. As a result, average cholesterol value during 3-weeks experiment was $3920.18 \pm 128.23 \mu \mathrm{g} / \mathrm{g}$. The RSD weeks $(3.27 \%)$ was less than RSD Horwitz (4.06\%), which confirmed that our modified method was sufficiently precise. Based on One way-ANOVA test results followed by Duncan's test, the egg cholesterol content at different weeks did not significantly differ ( $p>0.05)$. Hence, it can be stated that this method has a good reproducibility over a certain period of time.

\section{Application of the Validated Method in Different Eggs from the Market}

This validated method was applied for the determination of cholesterol in different eggs from the market. Cholesterol content of each egg was presented in Table 3 , in which it differed according to the type of eggs as follows: red local chicken eggs $>$ quail eggs $>$ duck eggs $>$ broiler chicken eggs $>$ low cholesterol eggs.

\section{DISCUSSION}

Cholesterol analysis was conducted according to the standard protocol of AOAC 994.10:2012 with modifications, in which the improvement was carried out at saponification steps. Sample preparation is a critical step in cholesterol analysis using RP-HPLC. Saponification constitutes initial and crucial step to release cholesterol from the other components since saponification was reported capable of improving cholesterol concentration in egg yolk compared to sample without saponification (John et al., 2015). The use of $\mathrm{KOH}$ in saponification enables to hydrolyze disrupting components such as fatty acids and acyl glycerides (Ahn et al., 2012; Park et al., 2013), while its effect may depend on the concentration and heating time (Salimon et al., 2012; Souza et al., 2017). The modification in this procedure was made at the following conditions, including less amount of sample ( $1 \mathrm{~g}$, from $6 \mathrm{~g}$ of standard method), $\mathrm{KOH}$ concentration, saponification time, and changing toluene with hexane for extraction. As reported by Albuquerque et al. (2016), the use of hexane for extracting complex food matrices such as eggs is more preferable than toluene. Toluene is reported to induce the formation of emulsion system; thus, the sample preparation time takes longer. This modified analytical cholesterol method has proved to reduce saponification time and $\mathrm{KOH}$ concentration of AOAC 994.10 method (AOAC, 2012a), from $70 \pm 10 \mathrm{~min}$ to $15 \mathrm{~min}$ saponification time and from $50 \%$ to $10 \%$ of $\mathrm{KOH}$ concentration.

This HPLC-MWD instrument has proved good instrumental performance. In literatures, LOD of HPLCdiode array detector (DAD) for quantification of cholesterol were 1 and $3 \mu \mathrm{g} / \mathrm{mL}$ (Albuquerque et al., 2016; Bavisetty and Narayan, 2015), while LOQ was found at 11 $\mathrm{g} / \mathrm{mL}$ (Albuquerque et al., 2016). Meanwhile, LOD and LOQ of HPLC-fixed wavelength detectors were observed at 5 and $16 \mu \mathrm{g} / \mathrm{mL}$, respectively (Stroher et al., 2012). In this case, the sensitivity of RP-HPLC-MWD instrument could be similar to that of HPLC-DAD and even higher than that of HPLC-fixed wavelength detector.

Our cholesterol analytical method tended to have a similar accuracy compared to several instruments operated with different detectors. Recovery of cholesterol analysis using HPLC-DAD (Bavisetty \& Narayan, 2015; Albuquerque et al., 2016) ranging from 95.2\%, 98\%, to $111 \%-125 \%$, respectively. The recovery of cholesterol analysis using HPLC-UV operated at fixed wavelength reached $84 \%-103 \%$; $93.34 \%-102.34 \%$; and $93.33 \pm 0.22 \%$

Table 3. Cholesterol contents of various eggs from market $(n=2)$

\begin{tabular}{lccc}
\hline \multicolumn{1}{c}{ Various eggs } & $\begin{array}{c}\text { Cholesterol } \\
\text { contents }(\mu \mathrm{g} / \mathrm{g})\end{array}$ & RSD (\%) & $\begin{array}{c}{ }^{*} \mathrm{RSDH} \\
(\%)\end{array}$ \\
\hline Quail & $4351.63 \pm 172.49$ & 3.96 & 4.53 \\
Duck & $4295.91 \pm 13.73$ & 0.32 & 4.54 \\
Red local chicken & $4692.51 \pm 74.64$ & 1.59 & 4.48 \\
Low cholesterol & $3146.83 \pm 68.69$ & 2.18 & 4.76 \\
Broiler chicken & $3918.20 \pm 58.87$ & 1.50 & 4.61 \\
\hline
\end{tabular}

Note: ${ }^{*} \mathrm{RSDH}=\mathrm{RSD}$ Horwitz.

Table 2. Accuracy and precision of validated method for determination of cholesterol in eggs using RP-HPLC-MWD (n=7)

\begin{tabular}{|c|c|c|c|c|c|}
\hline \multirow{2}{*}{$\begin{array}{c}\text { Spiked } \\
\text { concentration } \\
\text { ( } \mu \mathrm{g} / \mathrm{g} \text { sample) }\end{array}$} & \multicolumn{2}{|c|}{$\begin{array}{l}\text { Analyzed-spiked concentration } \\
(\mu \mathrm{g} / \mathrm{g} \text { sample })\end{array}$} & \multirow[t]{2}{*}{ Precision (\%) } & \multicolumn{2}{|c|}{ Accuracy (\%) } \\
\hline & Range & Mean & & Range & Mean \\
\hline 500 & $517.37-620.33$ & 561.30 & 1.05 & $103.47-124.07$ & 112.26 \\
\hline 5018 & $4236.62-5321.35$ & 4948.70 & 3.90 & $84.43-105.87$ & 98.62 \\
\hline
\end{tabular}

Note: Accuracy expressed by recovery; Precision expressed by RSD 
(Ahn et al., 2012; Mariutti et al., 2008; Stroher et al., 2012), while Lioe et al. (2013) found that the recovery value in HPLC-ELSD was $108 \%-122.13 \%$.

Previously, the validation of cholesterol analytical methods on diverse foodstuffs (sour cream, whole eggs, egg yolks, and some fish species) using HPLC-DAD demonstrated RSD analysis of $0.69 \%, 0.54 \%, 1.92 \%$, $3.05 \%$, respectively (Albuquerque et al., 2016; Bavisetty \& Narayan, 2015). In our present results, the precision value tended to be similar, even lower than that obtained from HPLC-DAD experiment, but what we achieved in this present study seemed to have better precision compared to that obtained from HPLC-ELSD experiment. The precisions were reported to reach $5.26 \%, 4.29 \%$, and $10.11 \%$ (Lioe et al., 2013). The reproducibility of cholesterol analytical method using HPLCELSD and HPLC-DAD in previous studies reached $2.25 \%$ and $1.75 \%$, respectively (Albuquerque et al., 2016; Lioe et al., 2013). Even though this reproducibility intralab value was larger than previous studies, this value still fulfilled the acceptability requirement.

Red chicken eggs were recognized as local egg, containing DHA and omega 3. Some studies reported lower cholesterol of DHA- and omega 3-enriched eggs compared to control eggs (Khan et al., 2017; Mattioli et al., 2016). On the other hand, Faitarone et al. (2013) reported that the addition of DHA and omega-3 in egg feed could not reduce the cholesterol concentration of eggs. In this study, the cholesterol content of quail and duck eggs seemed to be smaller than that reported by USDA (2018a, 2018b), i.e. 8440 and $8840 \mu \mathrm{g} / \mathrm{g}$, respectively. The cholesterol content could be higher due to the other factors, such as the age of the bird (Faitarone et al., 2013).

The cholesterol content of broiler chicken egg in the study was smaller than the previous report by Albuquerque et al. (2016), which reached up to 4390.00 $\mu \mathrm{g} / \mathrm{g}$. However, it was greater than the cholesterol concentration in whole chicken eggs, i.e. 3046.00-3062.00, $2368.73,562.68 \mu \mathrm{g} / \mathrm{g}$, as described by numerous preceding works (Lioe et al., 2013; Naviglio et al., 2012; Park et al., 2013). Cholesterol content of chicken eggs in this study was $3720 \mu \mathrm{g} / \mathrm{g}$, which was closed to that reported by USDA (2016) and Exler et al. (2013).

\section{CONCLUSION}

The validated cholesterol analytical method using RP-HPLC-MWD in sample preparation step could reduce the use of chemicals, saponification, and analysis time. It is more simple and efficient than standard method-AOAC 994.10:2012. This method can be applied to the other various eggs from the market.

\section{CONFLICT OF INTEREST}

Authors declare that they have no conflict of interest with Laboratory of Food Science and Technology, Faculty of Agricultural Technology, IPB University, Bogor, Indonesia that funded this research.

\section{ACKNOWLEDGEMENT}

The authors thank Laboratory of Food Science and Technology, Department of Food Science and Technology, Faculty of Agricultural Technology, IPB University, Bogor, Indonesia that funded this research. We also would like to thank Ririn Anggraeni as a laboratory technician for helping the conduction of this research.

\section{REFERENCES}

Abdurrahman, Z.H., Y.B. Pramono, \& N. Suthama. 2016. Meat haracteristic of crossbread local chicken fed inulin of dahlia tuber and Lactobacillus sp. Med. Pet. 39: 112-118. https:// doi.org/10.5398/medpet.2016.39.2.112

Ahn, J.H., I.S. Jeong, B.M. Kwak, D. Leem, T. Yoon, C. Yoon, J. Jeong, J.M. Park, \& J.M. Kim. 2012. Rapid determination of cholesterol in milk containing emulsified foods. Food Chem. 135: 2411-2417. https://doi.org/10.1016/j. foodchem.2012.07.060

Albuquerque, T.G., M.B.P.P. Oliveira, A. Sanches-silva, \& H.S. Costa. 2016. Cholesterol determination in foods: comparison between high performance and ultra-high performance liquid chromatography. Food Chem. 193:18-25. https://doi.org/10.1016/j.foodchem.2014.09.109

AOAC (Association of Official Analytical Chemists). 2012a. AOAC Official Method 994.10 Cholesterol in foods. J. AOAC Int. 2: 104-105.

AOAC (Association of Official Analytical Chemists). 2012b. AOAC Official Method 925.30 solids (total) in eggs, vacuum method. J. AOAC Int.

AOAC (Association of Official Analytical Chemists). 2012c. Appendix K: guidelines for dietary supplements and botanical. J. AOAC Int. 2:1-15.

AOAC (Association of Official Analytical Chemists). 2016. Appendix F: guidelines for standard method performance requirements. J. AOAC Int. 2: 1-18.

Bavisetty, S.C.B. \& B. Narayan. 2015. An improved RP-HPLC method for simultaneous analyses of squalene and cholesterol especially in aquatic foods. J. Food Sci. Technol. 52: 6083-6089. https://doi.org/10.1007/s13197-015-1793-4

Cais-Sokolinska, D., M. Rudzińska. 2018. Short communication : Cholesterol oxidation products in traditional buttermilk. J. Dairy Sci. 101: 3829-3834. https://doi.org/10.3168/ jds.2017-13942

Central Bureau of Statistics. 2017. The Average Consumption of Each Capita for a Week of a Variety of Important Food Ingredients, 2007-2016. https://www.bps.go.id/linkTabelStatis/view/id/950.[28 November 2017].

Chen, Y.Z., S.Y. Kao, H.C. Jian, Y.M. Yu, J.Y. Li, W.H. Wang, \& C.W. Tsai. 2015. Determination of cholesterol and four phytosterols in foods without derivatization by gas chromatography-tandem mass spectrometry. J. Food Drug Anal. 23: 636-644. https://doi.org/10.1016/j.jfda.2015.01.010

EURACHEM. 2014. Eurachem Guide: The Fitness for Purpose of Analytical Methods - A Laboratory Guide to Method Validation and Related Topics. 2nd Ed. www.eurachem. org. [08 November 2017].

Exler, J., K.M. Phillips, K.Y. Patterson, \& J.M. Holden. 2013. Cholesterol and vitamin D content of eggs in the U.S. retail market. J. Food Compos. Anal. 29: 110-116. https://doi. org/10.1016/j.jfca.2012.11.001

Faitarone, A., E. Garcia, R. Roca, H. Ricardo, E. Andrade, K. Pelicia, \& F. Vercese. 2013. Cholesterol levels and nutritional composition of commercial layers eggs fed diets with different vegetable oils. Braz. J. Poultry Sci. 15: 31-38. https://doi.org/10.1590/S1516-635X2013000100006 
[JECFA] Joint FAO/WHO Expert Committee on Food Additives. 2006. Combined Compendium of Food Additive Spesifications: Analytical Methods, Test Procedures and Laboratory Solutions Used by and Referenced in the Food Additive Specifications. Rome (Italy): Food and Agriculture Organization of The United Nations.

John, J., A. Reghuwanshi, U.K. Aravind, \& C.T. Aravindakumar. 2015. Development and validation of a high-performance thin layer chromatography method for the determination of cholesterol concentration. JFDA. 3: 2-7. https://doi. org/10.1016/j.jfda.2014.07.006

Khan, S.A., A. Khan, S. Khan, A. Beg, A. Ali, \& G. Damanhouri. 2017. Comparative study of fatty-acid composition of table eggs from the Jeddah food market and effect of value addition in omega-3 biofortified eggs. SAUDI J. Biol. Sci. 24: 929-935. https://doi.org/10.1016/j.sjbs.2015.11.001

Lioe, H.N., T. Setianingrum, \& R. Anggraeni. 2013. Method Validation of Cholesterol Analysis in Egg Using HPLCELSD. Indones. J. Agric. Sci. 18: 178-185.

Mariutti, L.R.B., C. Nogueira, \& N. Bragagnolo. 2008. Optimization and validation of analytical conditions for cholesterol and cholesterol oxides extraction in chicken meat using response surface methodology. J. Agric. Food Chem 56: 2913-2918. https://doi.org/10.1021/jf0735432

Mattioli, S., A.D. Bosco, M. Martino, S. Ruggeri, O. Marconi, V. Sileoni, B. Falcinelli, C. Castellini, \& P. Benincasa. 2016. Alfalfa and flax sprouts supplementation enriches the content of bioactive compounds and lowers the cholesterol in hen egg. J. Funct. Foods 22: 454-462. https://doi. org/10.1016/j.jff.2016.02.007

Min, J., S. Lee, M.I. Khan, D.G. Yim, K. Seol, M. Lee, \& C. Jo. 2015. Monitoring the formation of cholesterol oxidation products in model systems using response surface methodology. Lipids Health Dis. 14: 77. https://doi.org/10.1186/ s12944-015-0074-6

Naviglio, D., M. Gallo, L. Le, C. Scala, L. Ferrara, \& A. Santini. 2012. Determination of cholesterol in Italian chicken eggs. Food Chem. 132: 701-708. https://doi.org/10.1016/j. foodchem.2011.11.002
Park, J., I. Jeong, B. Kwak, J. Ahn, D. Leem, J. Jeong, \& J. Kim. 2013. Application of rapid sample preparation method and monitoring for cholesterol content in chicken egg and egg powder. Korean J. Food Sci. An. 33: 672-677. https:// doi.org/10.5851/kosfa.2013.33.5.672

Salimon, J., B.M. Abdullah, \& N. Salih. 2012. Saponification of jatropha curcas seed oil: optimization by d-optimal design. Int. J. Chem. Eng. 2012: 1-6. https://doi. org/10.1155/2012/574780

Santi, M.A, Sumiati, \& L. Abdullah. 2015. Cholesterol and malondialdehyde contents of broiler-chicken meat supplemented with indigofera zolingeriana top leaf meal. Med. Pet. 38: 163-168. https://doi.org/10.5398/medpet.2015.38.3.163

Souza, H.A.L., L.R.B. Mariutti, \& N. Bragagnolo. 2017. Microwave assisted direct saponification for the simultaneous determination of cholesterol and cholesterol oxides in shrimp. J. Steroid Biochem. Mol. Biol. 169: 88-95. https:// doi.org/10.1016/j.jsbmb.2016.03.027

Stroher, G.L., A.C. Rodrigues, L.F. Dias, M.R. Pedrão, L.N. De Paula, J.V. Visentainer, \& N.E. De Souza. 2012. Comparative analysis and validation methodologies of GC and HPLC for analysis of cholesterol in meat products. AJAC. 3: 306-311. https://doi.org/10.4236/ajac.2012.34042

Sunanti, S.T., Samin, \& C. Supriyanto. 2013. Determination of the candidate value of in-house reference material (RM) $\mathrm{ZrO}_{2}$ Indonesian Journal of Nuclear Science and Technology. 14: 23-36.

USDA (United States Department Agriculture). 2016. National Nutrient Database for Standars Reference Release 28: 01123, Egg, Whole, Raw, Fresh. https://ndb.nal.usda.gov/ ndb/search/list/. [2 September 2017].

USDA (United States Department Agriculture). 2018a. National Nutrient Database for Standars Reference Release 28: 01140, Egg, Quail, Whole, Fresh, Raw. https://ndb.nal. usda.gov/ndb/search/list/. [20 Oktober 2018].

USDA (United States Department Agriculture). 2018b. National Nutrient Database for Standars Reference Release 28: 01138, Egg, Duck, Whole, Fresh, Raw. https://ndb.nal. usda.gov/ndb/search/list/. [20 Oktober 2018].

Wolfender, J. 2009. HPLC in natural product analysis: the detection issue. Planta Med. 75: 719-734. https://doi. org/10.1055/s-0028-1088393 